\title{
Did waiting times really decrease following a service reorganization? Results from a retrospective study in a pediatric rehabilitation program in Québec
}

\section{Chantal Camden, Bonnie Swaine \& Mélanie Levasseur}

To cite this article: Chantal Camden, Bonnie Swaine \& Mélanie Levasseur (2013) Did waiting times really decrease following a service reorganization? Results from a retrospective study in a pediatric rehabilitation program in Québec, Disability and Rehabilitation, 35:9, 719-724, DOI: 10.3109/09638288.2012.705948

To link to this article: https://doi.org/10.3109/09638288.2012.705948

\section{曲 Published online: 16 Aug 2012.}

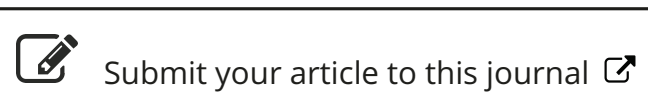

Wlll Article views: 352

Q View related articles $\sqsubset$

Citing articles: 2 View citing articles $\square$ 


\title{
Did waiting times really decrease following a service reorganization? Results from a retrospective study in a pediatric rehabilitation program in Québec
}

\author{
Chantal Camden ${ }^{1,2}$, Bonnie Swaine ${ }^{3,4,5}$ \& Mélanie Levasseur ${ }^{6,7}$ \\ ${ }^{1}$ Centre de Réadaptation Estrie, Sherbrooke, Québec, Canada, ${ }^{2}$ CanChild Centre for Childhood Disability Research, School of \\ Rehabilitation Science, McMaster University, Hamilton, Ontario, Canada, ${ }^{3}$ School of Rehabilitation, Université de Montréal, \\ Montreal, Québec, Canada, ${ }^{4}$ Centre of Interdisciplinary Rehabilitation Research, Montréal, Québec, Canada, ${ }^{5}$ Lucie-Bruneau \\ Rehabilitation Centre, Montréal, Québec, Canada, ${ }^{6}$ Research Centre on Aging, Health and Social Services Centre - University \\ Institute of Geriatrics of Sherbrooke (CSSS-IUGS), Sherbrooke, Québec, Canada, and 'Department of Rehabilitation, Faculty of \\ Medicine and Health Sciences, Université de Sherbrooke, Sherbrooke, Québec, Canada
}

Purpose: To examine changes in waiting times and types of services received before, during and after a pediatric rehabilitation service reorganization including new admission procedures; To compare waiting time data available in the program's administrative database and children's medical files. Method: Waiting time was defined as the time elapsed between referral and accessing a service provided by any clinician in the program (program waiting time) or by any clinician within a discipline (discipline-specific waiting time). Services were categorized as individual, group treatment, or other. ANOVAs and $X^{2}$ tests were used to examine changes in waiting times and type of services, respectively. Paired $T$-tests compared the program waiting times from the two databases. Results: Data were collected on 188 children (mean age: 4 years and 1 month). The program and occupational therapy waiting times were shorter following the service reorganization. For two disciplines, the proportion of children receiving individual treatment diminished over time, while group and other types of interventions increased. Program waiting times calculated using the two data sources did not differ significantly but differences in the available data highlighted administrative issues. Conclusions: Service reorganization can decrease waiting times and change the type of services offered over time.

Keywords: Accessibility to services, health services research, pediatric, program evaluation, quality of care, waiting times

\section{Background}

Around the world, access to rehabilitation for children with disabilities is challenged by long waiting times compromising

\section{Implications for Rehabilitation}

- Service reorganization can improve accessibility by reducing the first waiting times.

- More researches are needed to understand the impact of the changes in the type of services provided on service accessibility and service quality.

- Service accessibility should be monitored using accurate data extending beyond those routinely collected.

early intervention and children and family functioning [1-9]. Increasing the frequency of group treatments, reducing individual treatment times, reviewing admission procedures and implementing new models of services, are some of the strategies reported in the literature as having reduced waiting times; modifications in the programs are described but little details are given regarding how waiting times were calculated [7,10-12]. Despite that waiting time is broadly defined as the time elapsed from a «referral» for a service (starting point) and its delivery (ending point) $[3,13,14]$, standardized methods of calculation across populations from different settings are lacking $[7,15]$. As such, interpreting and comparing studies about waiting times are difficult and do not allow one to fully appreciate the impact of the various strategies on service accessibility.

Having a clear starting and ending point to calculate rehabilitation waiting times for children with disabilities is an important issue [7]. In Canada, the starting point is typically when the child is referred to a specialized rehabilitation center after being seen by a doctor. This «referral» may correspond

Correspondence: Chantal Camden, Centre de Réadaptation Estrie, 300 rue King Est, Bureau 200, Sherbrooke, Québec, J1G 1B1, Canada.

Tel: 1 (819) 346-8411. Ext: 43234. Fax: 1 (819) 346-4580. E-mail: chantal.camden@usherbrooke.ca

(Accepted June 2012) 
to either the date written on the referral form, when the rehabilitation facility received the referral, or when the child's file was analyzed and he or she was considered eligible for services. An even bigger concern relates to the ending point, or the date of the "first service», since a child can receive a variety of services, ranging from consultation to individual or group treatments [16]. Depending on how waiting times are operationally defined and calculated, the «first service» could even correspond to a telephone call to set up an appointment. According to the Québec Health and Social Services Ministry (HSSM), this telephone call should not be considered an ending date because no significant contact is made with the child or with his or her parent [14]. Administrative databases currently used to calculate waiting times do not usually differentiate between the types of service provided. To complicate matters, children with disabilities often require services from a variety of disciplines. We purport that waiting time calculations should consider the dates when the child was seen by each health professional to whom he or she was referred (e.g. by providing discipline-specific waiting times for each requested discipline) as opposed to being solely based on the date the child was seen by any therapist in a program. This would prevent an underestimation of waiting times (i.e. by having the ending point indicating the time when only one clinician gets involved with the child). In practice, however, we know from experience that many database systems calculate only one waiting time that stops running as soon as the child is seen by one therapist.

Issues related to waiting times became apparent to us in the context of our rehabilitation service reorganization project [11]. Specifically, while evaluating the impact on service accessibility by examining the programs' administrative database, we noticed that waiting times decreased over the course of the service reorganization. However, clinicians' concerns about the accuracy of these data led us to search for additional information about service accessibility. We subsequently examined the data provided in the children's medical files (where clinicians from different disciplines entered a description of services provided on specific dates), a potentially more accurate and complete database to describe service accessibility. Given the importance of evaluating initiatives aimed at improving accessibility to pediatric rehabilitation services and of having reliable and accurate administrative databases [4], it is important to report our experience with waiting time data to improve future research.

This study thus aimed to examine changes in waiting times and in the types of services received before, during and after a pediatric rehabilitation service reorganization. We also compared the waiting time data available within the program's administrative database with that from the children's medical files.

\section{Method}

\section{Setting and background}

Our service reorganization involved a program providing rehabilitation services to children with disability living in southern Québec, Canada. Although newborns are eligible, children are often older when they are referred to the program. Indeed, until a clear permanent disability is confirmed, children are seen by health professionals in the regional hospital or in community settings. The period of time children will receive services varies according to their needs and their diagnosis, but after 21 years old, children are no longer eligible - if they still have rehabilitation needs, they are transferred to the adult program within the same centre. At the time of our study, about 50 therapists from six disciplines worked in five sub programs (e.g. developmental delay and speech and language delays) providing mainly individual interventions. Before 2006, interdisciplinary rehabilitations teams provided yearly outpatient services to 1000 children. Nevertheless, the program's administrative database indicated that children had to wait for up to 3 years before receiving services. To address these long waiting times, in 2006, the program undertook a reorganization principally including new admission procedures and increased group and community interventions. The new admission procedures were perceived as the organizational changes having the greatest potential to diminish waiting times for a first service within the program [17]. Specifically, as soon as possible following referral, a social worker contacted the parent to discuss their priorities and the program's services (including community resources) and to determine the best services for their child. A larger study, approved by the ethics board of the Center of Interdisciplinary Rehabilitation Research of Montreal, was carried out to document the impact of this service reorganization on a random sample of 222 families receiving services from at least one discipline in the program before, during and after the organizational changes (for details see [11]). Results from this study highlighted that service quality was maintained during and after the service reorganization [11]. Moreover, an increased number of children were served and a reduction in waiting times was observed. The diminished waiting times was however based only on a preliminary analysis of data from the program's administrative database. More complete analyses of waiting times were conducted as part of the current study.

\section{Participants}

For the current study, data on accessibility were available for 188 families (34 of the original 222 families were excluded from the analyses: 32 children were referred before 2000 when waiting times were calculated differently, and two had missing data). Families were classified into three sampling groups: those referred to the program before the new procedures were pilot tested (before 1 September 2006), during the reorganization/piloting of new admission procedures and after the full implementation of the new admission procedures (between 1 September 2007 and 31 August 2009).

\section{Data sources and procedures}

Two data sources were used: the administrative database and the children's medical files. Both sources contained information documenting the history of the services received as soon as a child was referred to the program. Typically, when the program received a request for services for a child, an administrative form (f532) was created and inserted into his/her medical file. The date of reception of the request was written on this form and manually entered into the administrative database. This constitutes the starting date for the calculation 
in days of the program's first waiting time and the disciplinespecific waiting times using both data sources.

A clinical coordinator reviewed the child's medical information found in his or her file. Once a child was considered eligible to receive program services (e.g. had a permanent disability, as per the Québec Health Ministry definition), his/ her name was placed on a waiting list. The first clinician in the program who had a significant contact with the child or his/her family completed an administrative form (f120) also included in the child's medical file. The date written on the f120 was then manually entered into the administrative database and considered the ending date for the calculations of the program's waiting time for the database. The administrative database did not allow for the recording of information about the services provided by the various disciplines. This information could only be found in the medical file.

Three research assistants carefully reviewed all of the professional notes documented in the medical files and using a standardized procedure, identified the date when a significant contact first occurred between the child and or his/her family and a clinician from a particular discipline. This date was considered the ending date for the calculations of the program's first waiting time and the discipline-specific waiting times using the medical file data. Also from the medical files, the research assistants compiled the types of service provided. These services were categorized according to: (1) type of first service within the first month: (i) evaluation/monitoring (i.e. assessment without regular/weekly treatments), (ii) treatment (i.e. treatment on a regular/weekly basis without evaluation), or (iii) evaluation and treatment; (2) number of health professionals involved: (i) one clinician (unidisciplinary) or (ii) two or more clinicians (multidisciplinary); (3) number of children seen at the same time: (i) individual or (ii) group interventions (Table III). Services offered to family members or community partners involved with a particular child or group of children were classified within these same categories (e.g. information sessions for parents were classified as group interventions).

\section{Statistical analysis}

Descriptive statistics (mean and standard deviation or frequency and percentage) were performed to calculate waiting times. ANOVAs and $\chi^{2}$ tests were used to compare waiting times and type of services provided before, during and after the reorganization, respectively. For statistical purposes, type of services was recoded into one of three clinically significant categories: 1) individual treatments (with or without evaluation); 2) group treatments (with or without evaluation); 3) others (including mainly those who only had an evaluation). When statistical differences were identified in waiting times and type of services, two-by-two $\chi^{2}$ tests were calculated to locate the differences.

Paired T-tests compared the program's first waiting times recorded using the administrative database with those recorded in the medical files. A table of frequencies (based on waiting time categories inspired by the standards of the Québec HSSM [14]) was used to highlight differences potentially masked by analysis with mean values [18].

\section{Results}

On average, children were 4 years and 1 month (SD: 2 years and 8 months) old when they were referred to the program, $52.1 \%$ lived in the urban region and $48.9 \%$ received services from the speech and language delay sub program. Children referred to the program after the service reorganization were older ( 5 years and 7 months) than those referred before ( 3 years and 7 months $)(F=6.25 ; \mathrm{p}=0.02)$, which might reflect the increase of children over the past years with speech and language delays and dyspraxia, who are often older when they are referred to the program. However, no difference between the three subgroups was found with regards to children's sub programs or region of residence.

Based on the administrative database, program first waiting times decreased over the study period and statistical differences were found between those calculated before and after the reorganization (Table I). Based on medical file data, the service reorganization contributed to important reductions of all waiting times, but statically significant differences (before and after the reorganization) were found only for the program and the occupational therapy first waiting times. Over the 3 years, the reductions in waiting times ranged from $42 \%$ (waiting times for special education as per the medical files) to $80 \%$ (overall program waiting times using the administrative database). The number of children referred for services over the study period also greatly varied across discipline, ranging from 10 for neuropsychology to 143 for speech and language therapy (Table I).

According to the medical file, $45.7 \%$ of the program's first services were provided by a social worker and $30.9 \%$ of the services consisted of a telephone interview with parents (data not shown). Although a great variety of first services was provided, many children had only an evaluation within the first month (Table II). No changes were noted in the type of first services provided before, during and after the service reorganization for physiotherapy, occupational therapy and psychology. Specifically for speech and language therapy (Table III; $\chi^{2}=22.097, \mathrm{p}<0.01$ ) and special education $\left(\chi^{2}=10.5, \mathrm{p}=0.03\right)$, the frequency of individual treatments decreased across the study periods and group treatments and other types of interventions (such as evaluation and monitoring) increased. Although not statistically significant, the same tendency was observed for social work. Table III illustrates how services evolved over time in speech and language therapy (for tables illustrating changes in each of the discipline, see http://chantalcamden.weebly. com/publications.html).

No statistical differences were found when comparing the program's first waiting time calculated using the administrative database with those calculated with medical file data (Figure 1). Nevertheless, important specific variations were found (Figure 2). For instance, for 43 children (22.9\%), the difference in days between waiting times calculated by the administrative database compared to those calculated with medical file data was within $0-3$ days. In $10.1 \%$ of the cases, the administrative database underestimated waiting times from 31 to 90 days, and in $9.1 \%$ of the cases, between 3 months and 2 years. 
Table I. Waiting times (in days) for first services in the program and for each discipline calculated with data from the administrative database and from the medical files.

\begin{tabular}{|c|c|c|c|c|}
\hline \multirow[b]{2}{*}{ Discipline } & \multicolumn{4}{|c|}{ Mean (SD) } \\
\hline & $\begin{array}{l}\text { Total number of } \\
\text { children referred from } \\
2000 \text { to } 2009(\%)\end{array}$ & $\begin{array}{l}\text { Before the } \\
\text { reorganization }\end{array}$ & $\begin{array}{l}\text { During the } \\
\text { reorganization }\end{array}$ & $\begin{array}{l}\text { After the } \\
\text { reorganization }\end{array}$ \\
\hline \multicolumn{5}{|l|}{ Waiting time provided by the administrative database } \\
\hline Overall program (program’s first waiting time) & $188(100)$ & $153.8(207.5)$ & $88.6(79.6)$ & $31.0(31.3)^{\star}$ \\
\hline \multicolumn{5}{|l|}{ Waiting times provided by the medical files } \\
\hline Overall program (program’s first waiting time) & $188(100)$ & $149.75(140.21)$ & $104.49(100.72)$ & $50.71(31.87)^{*}$ \\
\hline Physiotherapy & $73(38.8)$ & $242.18(241.81)$ & $110.59(112.49)$ & $87.60(76.96)$ \\
\hline Occupational therapy & $124(66.0)$ & $345.26(278.04)$ & $270.82(264.41)$ & $143.58(91.58)^{*}$ \\
\hline Speech and language therapy & $143(76.1)$ & $273.66(287.07)$ & $220.47(204.34)$ & $139.91(70.90)$ \\
\hline Special education & $113(60.1)$ & $264.16(215.15)$ & $252.11(289.97)$ & $152.56(227.79)$ \\
\hline Social work & $60(31.9)$ & $100.40(111.69)$ & $113.08(90.72)$ & $53.73(39.40)$ \\
\hline Psychology and neuropsychology & $10(5.3)$ & $712.86(187.81)$ & N/A & $266.00(9.90)$ \\
\hline
\end{tabular}

${ }^{\star}$ Waiting times were significantly shorter $(\mathrm{p}<0.05)$ after the service reorganization compared to before.

N/A: Non applicable because only one child was referred in this discipline during this period.

Table II. Types of services offered during the first service for each discipline as recorded in the medical files (overall, during the 3-year period).

\begin{tabular}{|c|c|c|c|c|c|c|}
\hline \multirow[b]{3}{*}{ Type of service } & \multicolumn{6}{|c|}{ Discipline } \\
\hline & \multicolumn{6}{|c|}{ Number of children referred in each discipline (valid \%) ${ }^{\mathrm{a}}$} \\
\hline & $\mathrm{PT}(\mathrm{n}=73)$ & OT $(n=124)$ & SLT $(n=141)$ & $\mathrm{SE}(\mathrm{n}=113)$ & SW $(n=60)$ & Psy $(n=10)$ \\
\hline Unidisciplinary evaluation $^{\mathrm{b}}$ & $23(31.5)$ & $32(25.8)$ & $23(16.3)$ & $27(23.9)$ & $29(49.2)$ & $9(90)$ \\
\hline Unidisciplinary evaluation and individual treatment & $18(24.7)$ & $20(16.1)$ & $13(9.2)$ & $27(23.9)$ & $20(30.9)$ & $1(10)$ \\
\hline Unidisciplinary evaluation and group treatment & $0(0)$ & $4(3.2)$ & $2(1.4)$ & $1(0.9)$ & $0(0)$ & $0(0)$ \\
\hline Multidisciplinary evaluation & $16(21.9)$ & $37(29.8)$ & $36(25.5)$ & $6(5.3)$ & $0(0)$ & $0(0)$ \\
\hline Multidisciplinary evaluation and individual treatment & $15(20.5)$ & $10(8.1)$ & $1(0.7)$ & $7(6.2)$ & $1(1.7)$ & $0(0)$ \\
\hline Multidisciplinary evaluation and group treatment & $0(0)$ & $0(0)$ & $1(0.7)$ & $1(0.9)$ & $0(0)$ & $0(0)$ \\
\hline Unidisciplinary individual treatment & $0(0)$ & $4(3.2)$ & $6(4.3)$ & $10(8.8)$ & $4(6.8)$ & $0(0)$ \\
\hline Unidisciplinary group treatment & $0(0)$ & $6(4.8)$ & $19(13.5)$ & $3(2.7)$ & $0(0)$ & $0(0)$ \\
\hline Multidisciplinary group treatment & $1(1.4)$ & $6(4.8)$ & $34(24.1)$ & $24(21.2)$ & $5(8.5)$ & $0(0)$ \\
\hline Other (e.g. participation to a school plan of services) & $0(0)$ & $5(4.0)$ & $6(4.3)$ & $5(4.4)$ & $0(0)$ & $0(0)$ \\
\hline $\begin{array}{l}\text { Not available (children presumed to be still waiting } \\
\text { for services) }\end{array}$ & $0(0)$ & $0(0)$ & $0(0)$ & $2(1.8)$ & $0(0)$ & $0(0)$ \\
\hline \multicolumn{7}{|c|}{$\begin{array}{l}\text { aValid percent (\% calculated on the total number of children referred to each discipline). } \\
\text { bMonitoring is included under evaluation, as both are often done simultaneously. } \\
\text { OT, occupational therapy; Psy, psychology and neuropsychology; PT, physiotherapy; SE, special education; SLT, speech and language therapy; SW, social work. }\end{array}$} \\
\hline \multirow[b]{2}{*}{ Type of services } & \multicolumn{6}{|c|}{ Number of children (valid \%) ${ }^{\mathrm{a}}$} \\
\hline & \multicolumn{2}{|c|}{ Before $(n=84)$} & \multicolumn{2}{|c|}{ During $(\mathrm{n}=36)$} & \multicolumn{2}{|c|}{ After $(n=21)$} \\
\hline Unidisciplinary evaluation & \multicolumn{2}{|c|}{$18(21.4)$} & \multicolumn{2}{|r|}{$5(13.9)$} & \multicolumn{2}{|r|}{$0(0.0)$} \\
\hline Unidisciplinary evaluation and individual treatment & \multicolumn{2}{|c|}{$7(8.3)$} & \multicolumn{2}{|r|}{$4(11.2)$} & \multicolumn{2}{|r|}{$2(9.5)$} \\
\hline Unidisciplinary evaluation and group treatment & \multicolumn{2}{|c|}{$0(2.8)$} & \multicolumn{2}{|r|}{$1(2.8)$} & \multicolumn{2}{|r|}{$1(4.8)$} \\
\hline Multidisciplinary evaluation & \multicolumn{2}{|c|}{$28(33.3)$} & \multicolumn{2}{|r|}{$6(16.7)$} & \multicolumn{2}{|r|}{$2(9.5)$} \\
\hline Multidisciplinary evaluation and individual treatment & \multicolumn{2}{|c|}{$1(1.2)$} & \multicolumn{2}{|r|}{$0(0)$} & \multicolumn{2}{|r|}{$0(0.0)$} \\
\hline Multidisciplinary evaluation and group treatment & \multicolumn{2}{|c|}{$1(1.2)$} & \multicolumn{2}{|r|}{$0(0)$} & \multicolumn{2}{|r|}{$0(0.0)$} \\
\hline Unidisciplinary individual treatment & \multicolumn{2}{|c|}{$3(3.6)$} & \multicolumn{2}{|r|}{$3(8.3)$} & \multicolumn{2}{|r|}{$0(0.0)$} \\
\hline Unidisciplinary group treatment & \multicolumn{2}{|c|}{$11(13.1)$} & & $4(11.1)$ & & $4(19.0)$ \\
\hline Multidisciplinary group treatment & & $(14.3)$ & & $10(27.8)$ & & $12(57.1)$ \\
\hline Other (e.g. participation to a school plan of services) & & (3.6) & & $3(8.3)$ & & $0(0.0)$ \\
\hline
\end{tabular}

${ }^{a}$ Valid percent (\% calculated on the total number of children referred to speech and language therapy before, during and after the service reorganization).

\section{Discussion}

To our knowledge, this study is the first to use empirical data to examine important issues of access to rehabilitation services within a context of service reorganization. This article highlights that the reorganization of the program under study reduced waiting times by about $42-80 \%$. Previous studies have reported overall program waiting times decreasing as much as $70-85 \%[7,10,12]$, but did not document changes in waiting for different disciplines. To our knowledge, the current study is the first to report changes in waiting times for different disciplines and details about the variety of first types of services 


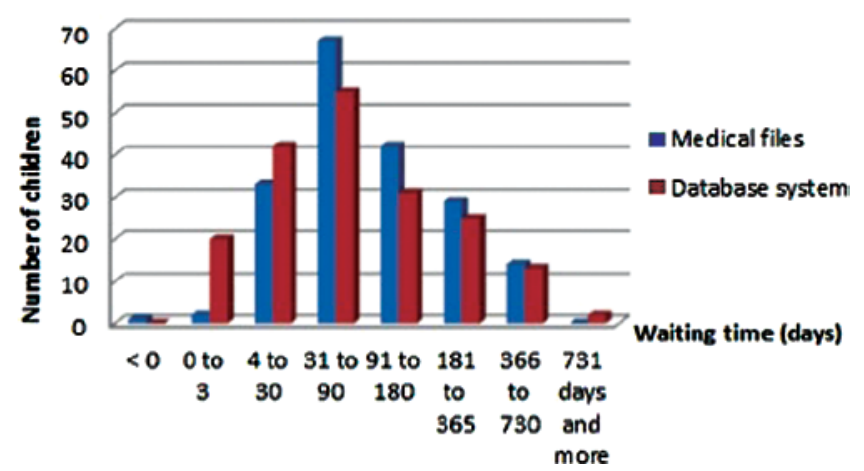

Figure 1. Waiting times for the program's first service for the administrative database and the medical file.

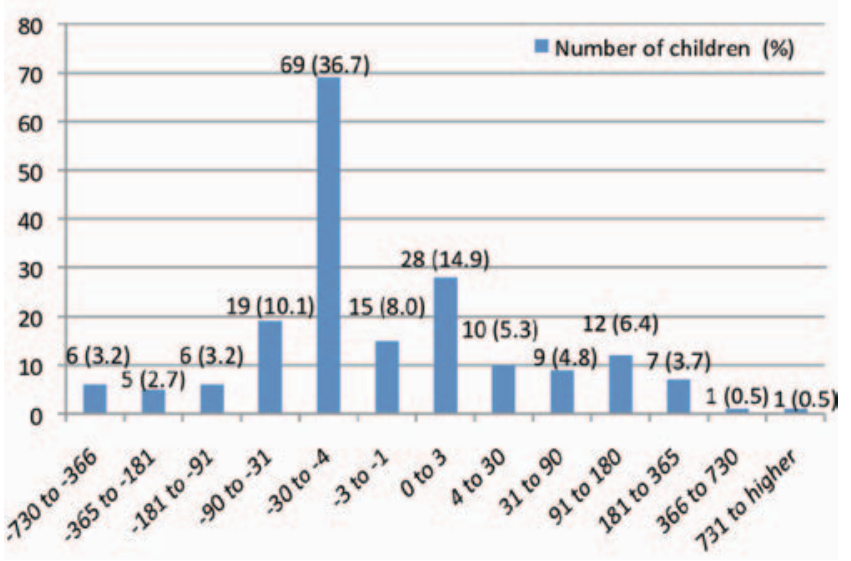

Figure 2. Differences in days between waiting times calculated by the administrative database compared to those calculated with medical file data: Number of children for each range of differences in days.

offered. These services evolved differently across disciplines during the service reorganization. For instance, over the years, multidisciplinary group treatments increased particularly in speech and language therapy, in special education and in social work. The increase for these three disciplines most probably reflects the increase in multidisciplinary group treatments provided within the speech and language delays subprogram where these three disciplines are particularly involved. Still, it would be interesting to investigate further how and why the type of services provided evolved differently across disciplines, and the impact of this on children's outcomes.

As monitoring/consultation and group interventions are more cost-effective than one-on-one interventions [17,1923], it might be expected that the disciplines having significantly increased their utilization of groups (i.e. speech and language therapy and special education) would be the ones with the most significant decrease in waiting times. However, our data confirmed that only occupational therapy waiting times decreased over time. Other factors thus probably influence waiting times, such as the children/clinician ratio. These results underscore the importance of considering various variables when evaluating service accessibility. The type of services offered within a program is probably one of the variables influencing service accessibility, and it probably also influences the quality of the services provided.
Our results on the type of first services provided also highlight that only a small percentage of the children actually received regular/weekly individual or group treatments within their first month of service. These results might reflect the fact that not every child requires treatment on a regular or weekly basis, as some children only need to be evaluated, counseled and monitored once in a while [16]. However, these results can also raise concerns about the appropriateness of the first services. Unfortunately, existing database systems do not allow one to evaluate if children really access the services they need.

Finally, this study raises concerns about the utilization of the program's administrative database (or similar databases) to accurately evaluate service accessibility. Although there were no statistical differences in the means provided by the program's database system compared to those calculated with medical file data, specific variations were found. Most important, the program's administrative database provided very limited information on service accessibility, as the type and discipline of the first service was not specified and subsequent waiting times for the different services could not be documented. These results suggest that studies reporting on the impact of service reorganization on accessibility using inhouse program databases should be interpreted with caution and have important implications for clinical and administrative practices.

\section{Implications for clinical and administrative practices}

Being able to obtain a complete and accurate portrait of waiting times is essential to develop, implement and evaluate creative initiatives aimed at improving service accessibility. To do so, clinical settings need a clear operational and standardized definition of waiting times, including the definition of starting and ending points. Midpoints might also be interesting to examine issues of waiting times. For instance, knowing the interval of time between referral (i.e. the date when request is sent) and when the child is eligible to receive services (i.e. date when the child is put on the waiting list), could possibly shed some light on the efficiency of the transfer agreements between facilities and the admission process. Ultimately, it could help accelerating children's admission into the rehabilitation program, to see them at a younger age. Once children are admitted to a program, calculating waiting times should also encourage discussion about the classification of different types of services offered to children and about what should be considered as a "significant contact." Moreover, different types of waiting times might need to be created (e.g. from referral or being accepted into the program to a first contact with the program, a consultation, an evaluation or a treatment with a professional from the different disciplines requested). A database system should provide a variety of waiting time indicators to offer a more complete picture of service accessibility.

The current priority given to reducing first waiting times is important, but could hide or create other accessibility issues. Since resource allocation needs to be planned to ensure responding well to children's needs across their life span, Gibson et al. warned against the risk of allocating the majority of the financial resources toward the first service and for 
early intervention [24]. In fact, accessibility should be monitored continuously to ensure that children are receiving the expected services at the right time. However, such monitoring involves many challenges. Indeed, settings should have care pathways describing clearly the services offered, with key milestone services that could be used to document service accessibility across the children's life span.

\section{Limits and futures directions}

This study has some limitations. First, although standardized procedures for the extraction of the information were used, the researchers had no control on how data were originally entered into the data sources. Some errors or variations could thus have occurred in the definition of the starting and ending dates. Secondly, the number of participants in each discipline and for each period of time was sometimes too small to detect significant changes.

Further investigations are needed to better understand and differentiate between different types of access to a program (program's first waiting times), to a therapist (each discipline's first waiting times), to the appropriate services and the link between waiting times and children's outcomes. Futures research should examine whether children's needs are adequately met when a first service is received. Such research would require more information on children (e.g. diagnosis but also the prognosis), on the services received (e.g. the type of service first received, but also subsequent services) and on the outcomes (e.g. functional outcomes linked to the services received).

\section{Conclusion}

The results of this study support the notion that service reorganization can be associated with improved accessibility to pediatric rehabilitation services. This article also underscores the importance of developing a broader vision of service accessibility by going beyond the traditional calculation of a program's first waiting time. Continuous quality improvement efforts of clinical settings still need a better understanding of the relationships between service accessibility, waiting times, type of services and service quality. Further research is warranted to support initiatives toward optimal service delivery models.

\section{Acknowledgements}

The authors thank all the families, clinicians and administrators who were involved in this study, and the research agents.

Declaration of Interest: At the time of the study, the first author was funded by scholarships from the Canadian Institutes of Health Research. The study was funded in part by the Québec Ministry of Health and Social Services and a Grant from the Office des Personnes Handicapées du Québec [Québec Office of Persons with Disability].

\section{References}

1. Bailey DB Jr, Hebbeler K, Scarborough A, Spiker D, Mallik S. First experiences with early intervention: a national perspective. Pediatrics 2004;113:887-896.

2. Ehrmann Feldman D, Couture M, Grilli L, Simard MN, Azoulay L, Gosselin J. When and by whom is concern first expressed for children with neuromotor problems? Arch Pediatr Adolesc Med 2005; 159:882-886.

3. Feldman DE, Champagne F, Korner-Bitensky N, Meshefedjian G. Waiting time for rehabilitation services for children with physical disabilities. Child Care Health Dev 2002;28:351-358.

4. Feldman DE, Swaine B, Gosselin J, Meshefedjian G, Grilli L. Is waiting for rehabilitation services associated with changes in function and quality of life in children with physical disabilities? Phys Occup Ther Pediatr 2008;28:291-304; discussion 305.

5. Grilli L, Feldman DE, Swaine B, Gosselin J, Champagne F, Pineault R. Wait times for paediatric rehabilitation. Healthc Policy 2007;2:e171-e187.

6. Mazer B, Feldman D, Majnemer A, Gosselin J, Kehayia E. Rehabilitation services for children: therapists' perceptions. Pediatr Rehabil 2006;9:340-350.

7. Miller AR, Armstrong RW, Mâsse LC, Klassen AF, Shen J, O'Donnell ME. Waiting for child developmental and rehabilitation services: an overview of issues and needs. Dev Med Child Neurol 2008;50:815-821.

8. Mitchell R, Unsworth C. Role perceptions and clinical reasoning of community health occupational therapists undertaking home visits. Aust Occup Ther J 2004;51:13-24.

9. Hadders-Algra M. Challenges and limitations in early intervention. Dev Med Child Neurol 2011;53 Suppl 4:52-55.

10. Bell A, Corfield M, Davies J, Richardson N. Collaborative transdisciplinary intervention in early years - putting theory into practice. Child Care Health Dev 2010;36:142-148.

11. Camden C, Swaine B, Tétreault S, Brodeur MM. Reorganizing pediatric rehabilitation services to improve accessibility: do we sacrifice quality? BMC Health Serv Res 2010;10:227.

12. Clow D, Mustafa A, Szollar J, Wood N, Reid J, Sinden S. Reducing waiting times associated with an integrated child health service. J R Soc Promot Health 2002;122:245-250.

13. Hadorn DC. Setting priorities for waiting lists: defining our terms. Steering Committee of the Western Canada Waiting List Project. CMAJ 2000;163:857-860.

14. Ministère de la santé et des services sociaux du Québec. Plan d’accès aux services pour les personnes ayant une déficience. Québec: Ministère de la santé et des services sociaux du Québec; 2008.

15. King S, Russell D, Rosenbaum P, Law M, Jaffer S. Scan of rehabilitation services for children and youth with complex needs. Hamilton CanChild Centre for Childhood Disability Research; 2004.

16. Palisano RJ, Murr S. Intensity of therapy services: what are the considerations? Phys Occup Ther Pediatr 2009;29:107-112.

17. Camden C, Tétreault S, Swaine B. Increasing the use of group interventions in a pediatric rehabilitation program: perceptions of administrators, therapists, and parents. Phys Occup Ther Pediatr 2012;32:120-135.

18. Levasseur M, Desrosiers J, St-Cyr Tribble D. Subjective Quality-of-Life Predictors for Older Adults with Physical Disabilities. Am J Phys Med Rehabil 2008;87:830-841.

19. Bayona CL, McDougall J, Tucker MA, Nichols M, Mandich A. Schoolbased occupational therapy for children with fine motor difficulties: evaluating functional outcomes and fidelity of services. Phys Occup Ther Pediatr 2006;26:89-110.

20. Coulter CL, Weber JM, Scarvell JM. Group physiotherapy provides similar outcomes for participants after joint replacement surgery as 1-to-1 physiotherapy: a sequential cohort study. Arch Phys Med Rehabil 2009;90:1727-1733.

21. Hung WW, Pang MY. Effects of group-based versus individual-based exercise training on motor performance in children with developmental coordination disorder: a randomized controlled study. J Rehabil Med 2010;42:122-128.

22. LaForme Fiss AC, Effgen SK. Use of groups in pediatric physical therapy: survey of current practices. Pediatr Phys Ther 2007;19:154-159.

23. LaForme Fiss AC, Effgen SK, Page J, Shasby S. Effect of sensorimotor groups on gross motor acquisition for young children with Down syndrome. Pediatr Phys Ther 2009;21:158-166.

24. Gibson BE, Darrah J, Cameron D, Hashemi G, Kingsnorth S, Lepage C, Martini R, et al. Revisiting therapy assumptions in children's rehabilitation: clinical and research implications. Disabil Rehabil 2009;31:1446-1453. 